\title{
Substance use and antisocial behavior: criterion-related validity of the Antisocial Process Screening Device in Mexican adolescents
}

\author{
Diana Mejía,' Silvia Morales-Chainé, ${ }^{2}$ Raquel García-Flores, ' Christian O. Acosta-Quiroz’
}

Departamento de Psicología, Instituto Tecnológico de Sonora, Ciudad Obregón, México.

2 Facultad de Psicología, Universidad Nacional Autónoma de México, Ciudad de México, México

\section{Correspondence:}

Diana Mejía Cruz

Departamento de Psicología, Instituto

Tecnológico de Sonora.

Calle 5 de Febrero 818 Sur,

Col. Centro,

Ciudad Obregón, Sonora, México.

Phone: +52 (644) 410 - 0900 ext

2454

Email: diana.mejia@itson.edu.mx

Received: 23 February 2019

Accepted: 19 September 2019

Citation:

Mejía, D., Morales-Chainé, S.

García-Flores, R., \& Acosta-Quiroz,

C. O. (2019). Substance use and antisocial behavior: criterion-related validity of the Antisocial Process Screening Device in Mexican adolescents. Salud Mental, 42(6), 275-279

DOI: $10.17711 /$ SM.0185-3325.2019.036

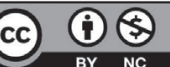

\begin{abstract}
Introduction. Adolescents who use drugs present several health problems, including criminal behavior. The Antisocial Process Screening Device (APSD) is a test that evaluates current conduct disorders in adolescents. Objective. This research carried out a cross-cultural adaptation of the APSD on Mexican population. Method. The original version of the APSD was translated into Mexican Spanish. The final version was administered to 1070 adolescents (958 students, 72 with minor faults, and 40 with criminal behavior) who completed the APSD and the ENCODE, the National survey on drug use. We computed correlations and regression models between APSD and ENCODE. We carried out a multivariate analysis to compare samples and quantity of drugs. Finally, we fitted the two-and three-factor models of the APSD with a CFA. Results. The APSD scores correlated significantly with all of the ENCODE variables. In the multivariate analysis, the variable quantity of drugs was significant to rise the APSD score $(F[3847]=7.53, p=.000)$. The CFA with three factors had the best fit. Reliability analysis suggests acceptable internal consistency $(\alpha=.79)$. Discussion and conclusion. Our results confirmed that the Mexican Spanish version of the APSD has good psychometric properties to be used in future research.
\end{abstract}

Keywords: Criminal behavior, adolescents, violence, substance-related disorders, impulse-control and conduct disorders.

\section{RESUMEN}

Introducción. Los adolescentes que consumen drogas presentan varios problemas de salud, incluida la conducta delictiva. El Test de Tamizaje de Proceso Antisocial (APSD, por sus siglas en inglés) es una prueba que evalúa los trastornos de conducta actual en adolescentes. Objetivo. Esta investigación realizó una adaptación intercultural de la APSD en población mexicana. Método. La versión original del APSD fue traducida al español de México. La versión final se administró a 1070 adolescentes (958 estudiantes, 72 con delitos menores y 40 con conducta delictiva) que completaron el APSD y la Encuesta Nacional de Consumo de Drogas en Estudiantes (ENCODE). Calculamos correlaciones y modelos de regresión entre APSD y ENCODE. Realizamos un análisis multivariado para comparar muestras y cantidad de drogas consumidas. Finalmente, ajustamos los modelos de dos y tres factores del APSD con un CFA. Resultados. Las puntuaciones APSD se correlacionaron significativamente con todas las variables ENCODE. En el análisis multivariado, la variable cantidad de drogas consumida fue significativa para incrementar el puntaje en APSD $(F[3847]=7.53, p=.000)$. El CFA con tres factores tuvo el mejor ajuste. El análisis de confiabilidad sugiere una consistencia interna aceptable $(\alpha=.79)$. Discusión y conclusión. Nuestros resultados confirmaron que la versión mexicana en español del APSD tiene adecuadas propiedades psicométricas para su utilización en futuras investigaciones.

Palabras clave: Comportamiento criminal, adolescentes, violencia, trastornos relacionados con sustancias, control de impulsos y trastornos de conducta. 


\section{INTRODUCTION}

Adolescents with substance-related disorders present serious health problems, and the correlation with school lag, criminal behavior, pregnancy, and family problems is high. There is evidence that the use of substances is related to violent behavior (Peltzer \& Pengpid, 2012).

Substance use disorder in adolescents has been associated in $75 \%$ of the cases with comorbidity of conduct disorder with limited prosocial emotions, oppositional defiant disorder, and attention-deficit hyperactivity disorder (Brook, Brook, Zhang, \& Koppel, 2010). Therefore, having an instrument to assess and detect the risk of developing behavioral and substance use problems in Mexican population is important.

One of the most important instruments to evaluate criminal behavior and antisocial personality in adolescents is the Antisocial Process Screening Device (APSD) developed by Frick, Bodin and Barry (2000). The instrument is a screening device to evaluate psychopathy based on the psychopathy Checklist-Revised (PCL-R) (Hare, 1991). The instrument originally evaluates three dimensions: narcissism, impulsivity, and Callous-Unemotional (CU). This factorial structure shows variants in the different countries where it has been adapted. The principal debate has been if two, three, or four dimensions are relevant to identify adolescents with potential psychopathy (de Weid, van der Baan, Raaijmakers, de Ruiter, \& Meeus, 2014; Laajasalo et al., 2014; Pechorro, Gonçalves, Andershed, \& DeLisi, 2017; Shaffer et al., 2016; Van Damme, Colins, \& Vanderplasschen, 2016). Nevertheless, the APSD shows general good psychometric properties. The criteria validation of APSD has demonstrated to be useful not only for clinical psychology but also for forensics due to the sensitivity and specificity on detecting criminal behavior and conduct disorders (Shaffer et al., 2016; Van Damme et al., 2016). However, the narcissism and impulsivity subscales have shown higher correlation with violent behavior than $\mathrm{CU}$, this last subscale needs further research which in theory is implied in the development of antisocial personality disorder (Frick \& Ray, 2015).

The aim of this research was to call out a translation and cross-cultural adaptation of the APSD for the Mexican population and to analyze its psychometric properties (criterion-related validity, and reliability) in this setting. The present study also contributes to the analysis of the factorial structure of the APSD (construct validity) in Latin American cultures besides evaluating its forensic utility in regards to criminal and drug use behavior.

\section{METHOD}

\section{Participants and procedure}

We worked within three samples in the northwest region of Mexico: Public school students enrolled in junior high school and high school, juvenile detention centers for minor faults (e.g., drug consumption in public places; assaults to private property; quarrels), and imprisonment within juvenile detention centers. They were provided with recruitment materials presenting the details of the study. Once the permission had been granted, the participants completed a series of self-report questionnaires, including the self-report APSD. This study was approved by the ethics committee of the Psychology Department in the Sonora Institute of Technology.

\section{Measures}

We obtained written authorization from one of the authors of the original version of the APSD (Frick et al., 2000), Professor Paul J. Frick, to perform a cross-cultural adaptation of the instrument for the Mexican population. The translation and Mexican context adaptation was done by two clinical psychologists (two of the authors: DM and SMC). This translation was sent to three clinical psychologists, who are experts in antisocial behavior (Addiction psychology, Master's degree). The reviewers' feedback was integrated into the final version. We followed the retroversion procedure according test translation guidelines with a native speaker (Hambleton, 2001).

Beside the self-report APSD (20 items), the participants also completed 114 items from the national survey of drug consumption in students ENCODE (Villatoro et al., 2015). The survey consisted of: number of criminal behavior (12 items), drug abuse (11 items), bullying (10 items), violence observation within the family (10 items), self-esteem ( 9 items), anxiety ( 8 items), maternal abuse (24 items) and parental abuse (24 items), and care neglect (6 items).

\section{Statistical analysis}

The data were analyzed using the SPSS v.24 (Arbuckle, 2012). A normality analysis (Kolmogorov-Smirnov test and Shapiro/Wilk test) was carried out for each variable to determinate whether use parametric or no parametric test of correlation and intergroup comparison. For the criterion-related validity analysis, we computed Pearson correlations and regression model among the APSD total score and the total score in the ENCODE scales: total of conduct disorder (CD), total of violence observation (VO), total of drug problems (DP), total of bullying problems (BP), total of self-esteem (SE), total of anxiety (AA), total of maternal and parental abuse (MA, PA), and total of neglect care (NC). We used all the sample to make this analysis. Then we made a multivariate analysis to compare three samples and the quantity of drug consumption as two factor variables, and the same variables used in the regression including the total APSD score. For the construct validity, we used AMOS v. 23 (Arbuckle, 2012). We fitted the two and three-factor models 
of the APSD (Frick et al., 2000) by kind of sample, and compared the two models. For the confirmatory factorial analysis (CFA), we used the maximum likelihood (ML) method (Byrne, 2010; Tarka, 2017). The Model fit was assessed using $\chi^{2}$, root mean square error of approximation (RMSEA), Tucker-Lewis index (TLI), and comparative fit index (CFI) (Jackson, Gillaspy, \& Purc-Stephenson, 2009; Byrne, 2010). We used the following cut-off scores: RMSEA scores below .05 indicate good fit, whereas scores between .05 and .08 indicate acceptable fit. A CFI score of .95 or above indicates excellent fit, and TLI score .95 or more indicates good fit (Hu \& Bentler, 1999). With regard to chi square, a good fit is indicated when $\chi^{2} / d f \leq 2$, whereas $\chi^{2} / d f \leq 3$ is indicative of an acceptable fit (Schermelleh-Engel, Moosbrugger, \& Müller, 2003). The assessment of reliability was done by the analysis of internal consistency (Cronbach's $\alpha$ ).

\section{RESULTS}

Data were collected from 1070 participants (958 students from public school, 72 from the juvenile detention centers for minor faults, and 40 from the Imprisonment within juvenile detention center). The ages of the participants ranged between 11 and 28 years. From the students-sample $(M=14.72, S D=1.79)$, minor faults $(M=15.43, S D=1.22)$, detention center $(M=17.78, S D=2.43)$. According to gender, the samples were: in schools $(50.4 \%$ men $)$, minor faults ( $86 \%$ men), and detention center (100\% men).

The dependent measures had $p$ values $>.05$ in the Kolmogorov-Smirnov test and Shapiro/Wilk test. The APSD scores correlated significantly with all the ENCODE variables: VO $(r=.163, p=.01), \mathrm{CD}(r=.345$, $p=.01), \mathrm{B}(r=.341, p=.01), \mathrm{SE}(r=-.241, p=.01), \mathrm{AA}$ $(r=.347, p=.01), \mathrm{PD}(r=.341, p=.01), \mathrm{MA}(r=.348$, $p=.01), \mathrm{CN}(r=.205, p=.01), \mathrm{PA}(r=.312, p=.01) . \mathrm{In}$ the regression analyses to predict APSD score, we found a significant model $(F[9849]=44.73, p<.000)$. Parental abuse and care neglect were no significant predictors $(p>$ $.05)$. While the anxiety and drug problems had more impact in the model, respectively $(\beta=.217, \beta=.169)$. The amount of variance explained with the model was $31.4 \%$. For all predictors, collinearity values were acceptable, with the variance inflation factor ranging from 1.072 to 1.74 . In the multivariate analysis, the independent variables (sample and quantity of drugs) did not have a significant interaction in almost none of the dependent variables, including APSD $(p>.05)$. We found interaction in the variables CD $\left(F\left[\begin{array}{l}6 \\ 847\end{array}\right]=2.63, p=.015\right)$, and DP $(F[6$ 847] $=6.14$, $p=.000)$. The variable sample had it main effect in the variables $\mathrm{MA}(F[2847]=5.36, p=.005), \mathrm{NC}(F[2847]$ $=3.84, p=.022)$, and SE $(F[2847]=5.01, p=.007)$. We found a main effect with the variable quantity of drug consumption in the variables $\operatorname{APSD}(F[3847]=7.53, p=.000)$,

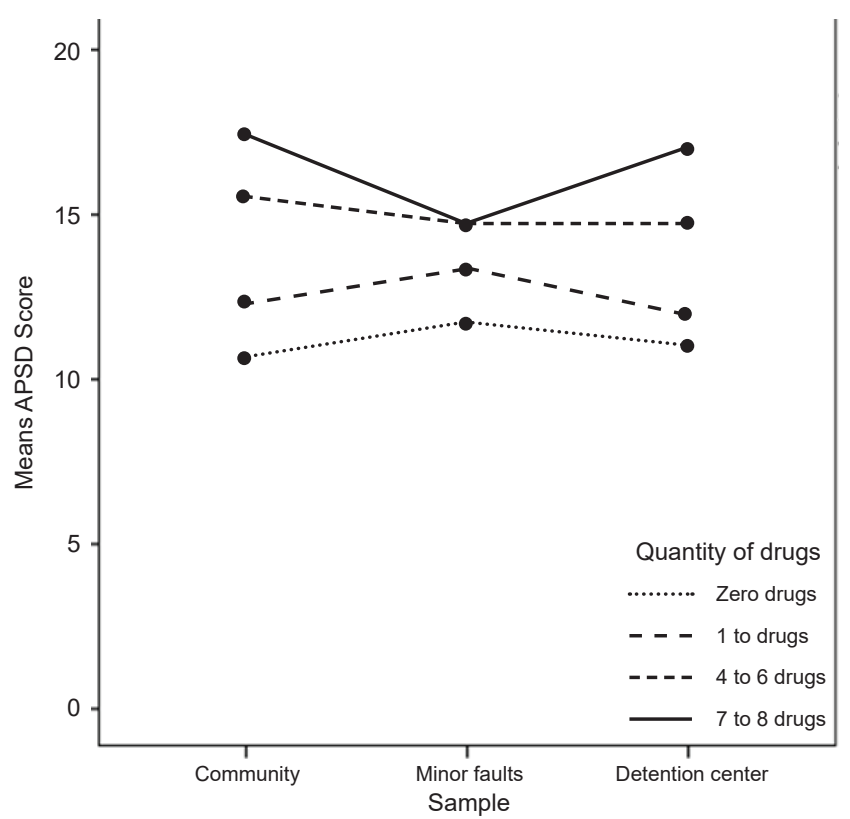

Figure 1. Interaction number of drugs and kind of sample in the APSD score.

$\mathrm{AA}(F[3847]=6.01, p=.000)$, and PA $(F[3847]=10.68$, $p=.000)$. The post hoc analysis with Tukey Test showed significant differences between community sample and the two forensic samples in the variables APSD, CD, DP, SE, MA, and NC $(p<.05)$. In the quantity of drugs, we found with the Tukey Test significant differences between used zero to three drugs and four to nine drugs in the variables PA, AA, and APSD $(p<.05)$, the scores increased in all the variables with the quantity of drugs (Figure 1). The CFA with three factors had the best fit when items 2 and 13 were deleted (Table 1). Reliability analysis suggests acceptable internal consistency $(\alpha=.79)$. The factors have the following values: impulsivity $\alpha=.70, \mathrm{CU} \alpha=.31$, narcissism $\alpha=.64$.

\section{DISCUSSION AND CONCLUSION}

This is a study report of the adaptation of the APSD to Mexican population. We reported its reliability and criteria validation with drug consumption and conduct disorder. The total APSD scores have significant positive correlations with conduct disorder, bullying, anxiety, problems with drugs, maternal abuse, care neglect, parental abuse and a negative correlation with self-esteem. The regression analysis shows that drug problems and conduct disorder are the best predictors of the APSD score in the sample. These facts imply that the APSD Mexican version has a good criteria validation, which is similar to other studies (de Weid et al., 2014; Laajasalo et al., 2014; Pechorro et al., 2017; Shaffer et al., 2016; Van Damme et al., 2016). 
Table 1

Confirmatory factor analysis in the forensic and community samples

\begin{tabular}{llllllll}
\hline Model & \multicolumn{1}{c}{$X^{2}$} & $d f$ & $X^{2} / d f$ & $R M S E A$ & $90 \% \mathrm{Cl}$ & $T L I$ & $C F I$ \\
\hline Total sample & & & & & & & \\
$\quad$ Two-factor & 984.4 & 169 & 5.82 & .067 & $(.063-.071)$ & .768 & .794 \\
$\quad$ Three-factor & 732.257 & 132 & 5.54 & .065 & $(.061-.070)$ & .797 & .825 \\
$\quad$ Three-factor (exc 2 \&13) & 171 & 132 & 4.58 & .580 & $(.053-.063)$ & .846 & .867 \\
Community & & & & & & & \\
$\quad$ Two-factor & 896.609 & 169 & 5.30 & .067 & $(.063-.071)$ & .773 & .798 \\
$\quad$ Three-factor & 681.86 & 132 & 5.16 & .066 & $(.610-.71)$ & .790 & .825 \\
$\quad$ Four-factor & 592.04 & 132 & 4.48 & .060 & $(.055-.065)$ & .837 & .859 \\
$\quad$ Forensic & & & & & & & \\
$\quad$ Two-factor & 310.2 & 169 & 1.83 & .087 & $(.710-.102)$ & .601 & .645 \\
$\quad$ Three-factor & 243.59 & 132 & 1.84 & .087 & $(.070-.104)$ & .616 & .669 \\
$\quad$ Three-factor (exc 2 \&13) & 208.63 & 132 & 1.58 & .072 & $(.530-.090)$ & .734 & .771 \\
\hline
\end{tabular}

The APSD originally showed three dimensions by confirmatory factor analysis (CFA), and several studies have confirmed this factorial structure (Frick et al., 2000; Laajasalo et al., 2014); However, some studies have found two factor solutions supported by CFA (de Weid et al., 2014; Fite, Greening, Stoppelbein, \& Fabiano, 2009). In contrast, other studies have found a better fit in community samples with the three-factor model than forensic or clinical samples (Shaffer et al., 2016). The current study compared the two-factor model and the three-factor model. We found a better fit with the three-factor model when we excluded items 2 and 13. The three-factor model obtained adequate fit indexes for both samples; these are: RMSEA $<.05, \mathrm{X}^{2} / \mathrm{df}<5$ (Jackson et al., 2009), TLI and CFI indexes do not represent a good fit in the three different models in the community and forensic samples. However, these difficulties have been seen in other countries validations (de Weid et al., 2014; Laajasalo et al., 2014; Pechorro et al., 2017; Shaffer et al., 2016; Van Damme et al., 2016). The reliability of the scale is acceptable, but the CU reliability is low, as it has been shown in other studies (Frick \& Ray, 2015). Which implies further research in the Latin American population about the limited prosocial emotions. We suggest to incorporate biological correlates and cognitive tasks. This could help to elucidate the reason as to why these dimensions show difficulties in their measurements.

Finally, we found an interesting effect between the quantity of drugs and the APSD score, where the involvement of drug usage/consumption raises antisocial behavior, even in the community sample. Some studies have found that drugs damage the brain especially the frontal lobe which implies a more impulsive behavior and low self-regulation (Kalivas \& O'Brien, 2008). The drugs effect makes us reconsider psychopathic or antisocial personality disorders as a disorder that can decrease the intensity of its symptoms when people stop using drugs. This is what Fridell, Hesse, and Billsten (2007) found in a five and fifteen fol- low-up, where criminal behavior had a significant reduction when people stopped using drugs, even with antisocial personality disorder.

One of the principal limitations in this research is the cross-sectional design. It is important to include follow-ups in the three samples that we had. In order to have a more precise picture of the APSD reliability. We suggest that future studies include multilevel analysis to control demographic variables and psychiatric comorbidity, and evaluate executive functions as a measure of frontal lobe problems. This last point is very important due raise rates of drug use in Mexican adolescents (Villatoro et al., 2017). And the fact that the drug use in adolescence affects executive functions in adulthood (Pope, Boomhower, Hutsell, Teixeira, \& Newland, 2016). We need future research using the APSD test to verify the screening performance to make it a useful tool in schools and clinical centers. The APSD could help us to provide prevention and treatment for the Mexican population.

\section{Funding}

This study received financial support from the Sonora Institute of Technology (PROFAPI_2018_0071).

\section{Conflict of interest}

The authors report no conflicts of interest.

\section{REFERENCES}

Arbuckle, J. L. (2012). Users Guide. IBM ${ }^{\circledR} S P S S^{\circledR} \operatorname{Amos}^{\text {TM }} 21$. Amos Development Corporation.

Brook, D. W., Brook, J. S., Zhang, C., \& Koppel, J. (2010). Association between attention-deficit/ hyperactivity disorder in adolescence and substance use disorder in adulthood. Archives of Pediatrics and Adolescent Medicine, 164(10), 930-934. doi: 10.1001/archpediatrics.2010.180

Byrne, B. (2010). Structural equation modeling with AMOS: Basic concepts, applications, and programming (3rd. ed.). New York, USA: Routledge.

de Weid, M., van der Baan, H., Raaijmakers, Q., de Ruiter, C., \& Meeus, W. (2014). Factor structure and construct validity of the Dutch version of the antisocial process screening device. Journal of Psychopathology and Behavioral Assessment, 36(1), 84-92. doi: 10.1007/s10862-013-9371-4 
Fite, P. J., Greening, L., Stoppelbein, L., \& Fabiano, G. A. (2009). Confirmatory factor analysis of the antisocial process screening device with a clinical inpatient population. Assessment, 16(1), 103-114. doi: 10.1177/1073191108319893

Frick, P. J., \& Ray, J. V. (2015). Evaluating Callous-Unemotional Traits as a Personality Construct. Journal of Personality, 83(6), 710-722. doi: 10.1111/ jopy. 12114

Frick, P. J., Bodin, S. D., \& Barry, C. T. (2000). Psychopathic traits and conduct problems in community and clinic-referred samples of children: Further development of the psychopathy-screening device. Psychological Assessment, 12(4), 382-393. doi: 10.1037/1040-3590.12.4.382

Fridell, M., Hesse, M., \& Billsten, J. (2007). Criminal behavior in antisocial substance abusers between five and fifteen years follow-up. American Journal on Addictions, 16(1), 10-14. doi: 10.1080/10550490601077734

Hambleton, R. K. (2001). The next generation of the ITC test translation and adaptation guidelines. European Journal of Psychological Assessment, 17(3), 164-172. doi: 10.1027//1015-5759.17.3.164

Hare, R. D. (1991). Manual for the Hare psychopathy checklist-revised. Ontario Canada: Multi-Health Systems.

Hu, L. T., \& Bentler, P. M. (1999). Cutoff criteria for fit indexes in covariance structure analysis: Conventional criteria versus new alternatives. Structural Equation Modeling, 6(1), 1-55. doi: 10.1080/10705519909540118

Jackson, D. L., Gillaspy, Jr. J. A., \& Purc-Stephenson, R. (2009). Reporting practices in confirmatory factor analysis: an overview and some recommendations. Psychological Methods, 14(1) 6-23. doi: 10.1037/a0014694

Kalivas, P. W., \& O’Brien, C. (2008). Drug addiction as a pathology of staged neuroplasticity. Neuropsychopharmacology, 33(1), 166-180. doi: 10.1038/ sj.npp.1301564

Laajasalo, T., Saukkonen, S., Kivivuori, J., Salmi, V., Lipsanen, J., \& Aronen, E. T. (2014). Brief report: self-reported psychopathic-like features among Finnish community youth: Investigation of the factor structure of the antisocial personality screening device. Journal of Adolescence, 37(7), 1185-1188. doi: 10.1016/j.adolescence.2014.08.010

Pechorro, P., Gonçalves, R. A., Andershed, H., \& DeLisi, M. (2017). Female psychopathic traits in forensic and school context: Comparing the antisocial process screening device self-report and the youth psychopathic traits inventoryshort. Journal of Psychopathology and Behavioral Assessment, 39(4), 642-656. doi: 10.1007/s10862-017-9605-y
Peltzer, K., \& Pengpid, S. (2012). Injury and social correlates among in-school adolescents in four Southeast Asian countries. International Journal of Environmental Research and Public Health, 9(8), 2851-2862. doi: 10.3390/ ijerph9082851

Pope, D. A., Boomhower, S. R., Hutsell, B. A., Teixeira, K. M., \& Newland, M. C. (2016). Chronic cocaine exposure in adolescence: Effects on spatial discrimination reversal, delay discounting, and performance on fixed-ratio schedules in mice. Neurobiology of Learning and Memory, 130, 93-104. doi: 10.1016/j.nlm.2016.01.017

Shaffer, C., Gatner, D., Gray, A. L., Douglas, K. S., Viljoen, J. L., Tweed, R., .. Gagnon, N. (2016). Incremental and predictive validity of the antisocial process screening device in a community sample of male and female ethnic minority and caucasian youth. Journal of Abnormal Child Psychology, 44(8), 1599-1612. doi: 10.1007/s10802-016-0130-3

Schermelleh-Engel, K., Moosbrugger, H., \& Müller, H. (2003). Evaluating the fit of structural equation models: Tests of significance and descriptive goodness-of-fit measures. Methods of Psychological Research, 8(2), 23-74.

Tarka, P. (2017). The comparison of estimation methods on the parameter estimates and fit indices in SEM model under 7-point Likert scale. Archives of Data Science, 2(1). doi: 10.5445/KSP/1000058749/10

Van Damme, L., Colins, O. F., \& Vanderplasschen, W. (2016). The limited prosocial emotions specifier for conduct disorder among detained girls: A multi-informant approach. Criminal Justice and Behavior, 43(6), 778-792. doi: $10.1177 / 0093854815613104$

Villatoro-Velázquez, J. A., Oliva-Robles, N., Fregoso-Ito, D., Bustos-Gamiño, M., Mujica-Salazar, A., Martín del Campo Sánchez, R., \& Medina-Mora, M E. (2015). Encuesta Nacional de Consumo de Drogas en Estudiantes 2014: Reporte de Drogas. México: Instituto Nacional de Psiquiatría Ramón de la Fuente Muñiz, Comisión Nacional Contra las Adicciones, Secretaría de Salud.

Villatoro-Velázquez, J. A., Oliva-Robles, N., Fregoso-Ito, D., Bustos-Gamiño, M., Mujica-Salazar, A., Martín del Campo Sánchez, R., \& Medina-Mora, M. E. (2017). Encuesta Nacional de Consumo de Drogas, Alcohol y Tabaco: Reporte de Drogas. México: Instituto Nacional de Psiquiatría Ramón de la Fuente Muñiz, Comisión Nacional Contra las Adicciones, Secretaría de Salud. 